\title{
Fault Diagnostic Method Based on Deep Learning and Multi-model Feature Fusion for Complex Industrial Processes
}

Zhichao Li, Li Tian, Qingchao Jiang, Xuefeng Yan*

${ }^{*}$ Corresponding Author: Xuefeng Yan

Email:xfyan@ecust.edu.cn

Address: P.O. BOX 293, MeiLong Road NO. 130, Shanghai 200237, P. R. China

Tell: 0086-21-64251036 
Key Laboratory of Advanced Control and Optimization for Chemical Processes of Ministry of Education, East China University of Science and Technology, Shanghai 200237, P. R. China 
Table S1. Results of feature selection for each fault and the structures of SAEs

\begin{tabular}{|c|c|c|}
\hline Fault No. & Results of feature selection & $\begin{array}{l}\text { Structures of } \\
\text { SAE }\end{array}$ \\
\hline IDV (0) & $1,2,3, \ldots, 51,52$ & $52-39-30-22$ \\
\hline IDV (1) & $44,17,4,1,18,45,34,20,10$ & $9-7-5-4$ \\
\hline IDV (2) & $\begin{array}{l}47,17,28,10,4,3,16,43,22,45,6 \\
34,18,1,39,2,7,50,42,11,24,35\end{array}$ & $22-17-12-9$ \\
\hline IDV (4) & 51,31 & $2-3-2-1$ \\
\hline IDV (5) & 52,20 & $2-3-2-1$ \\
\hline $\operatorname{IDV}(6)$ & $\begin{array}{c}44,1,33,20,4,23,30,21,25,10,24 \\
29,16,32,31,8,22,27,7\end{array}$ & $19-14-11-8$ \\
\hline IDV (7) & $45,17,38$ & $3-3-3-2$ \\
\hline IDV (8) & $\begin{array}{c}29,47,34,16,38,1,19,4,30,20, \\
5,13,28,44\end{array}$ & $14-11-8-6$ \\
\hline $\operatorname{IDV}(10)$ & $50,38,5,3,18$ & $5-4-3-2$ \\
\hline IDV (11) & $51,41,9,7$ & $4-3-2-2$ \\
\hline IDV (12) & $18,22,20,35,8,11,4,16,38$ & $9-7-5-4$ \\
\hline IDV (13) & $\begin{array}{c}19,2,38,34,46,18,21,31,50,15 \\
28,47,33,3\end{array}$ & $13-10-7-5$ \\
\hline IDV (14) & $9,21,38,28,51$ & $5-4-3-2$ \\
\hline $\operatorname{IDV}(16)$ & $50,40,16,17,19$ & $5-4-3-2$ \\
\hline IDV (17) & $21,12,9$ & $3-3-3-2$ \\
\hline IDV (18) & 31,52 & $2-3-2-1$ \\
\hline $\operatorname{IDV}(19)$ & $5,46,41$ & $3-3-3-2$ \\
\hline IDV (20) & $13,41,11$ & $3-3-3-2$ \\
\hline
\end{tabular}


Table S2. Confusion matrix of the classification results for MMFF-FD

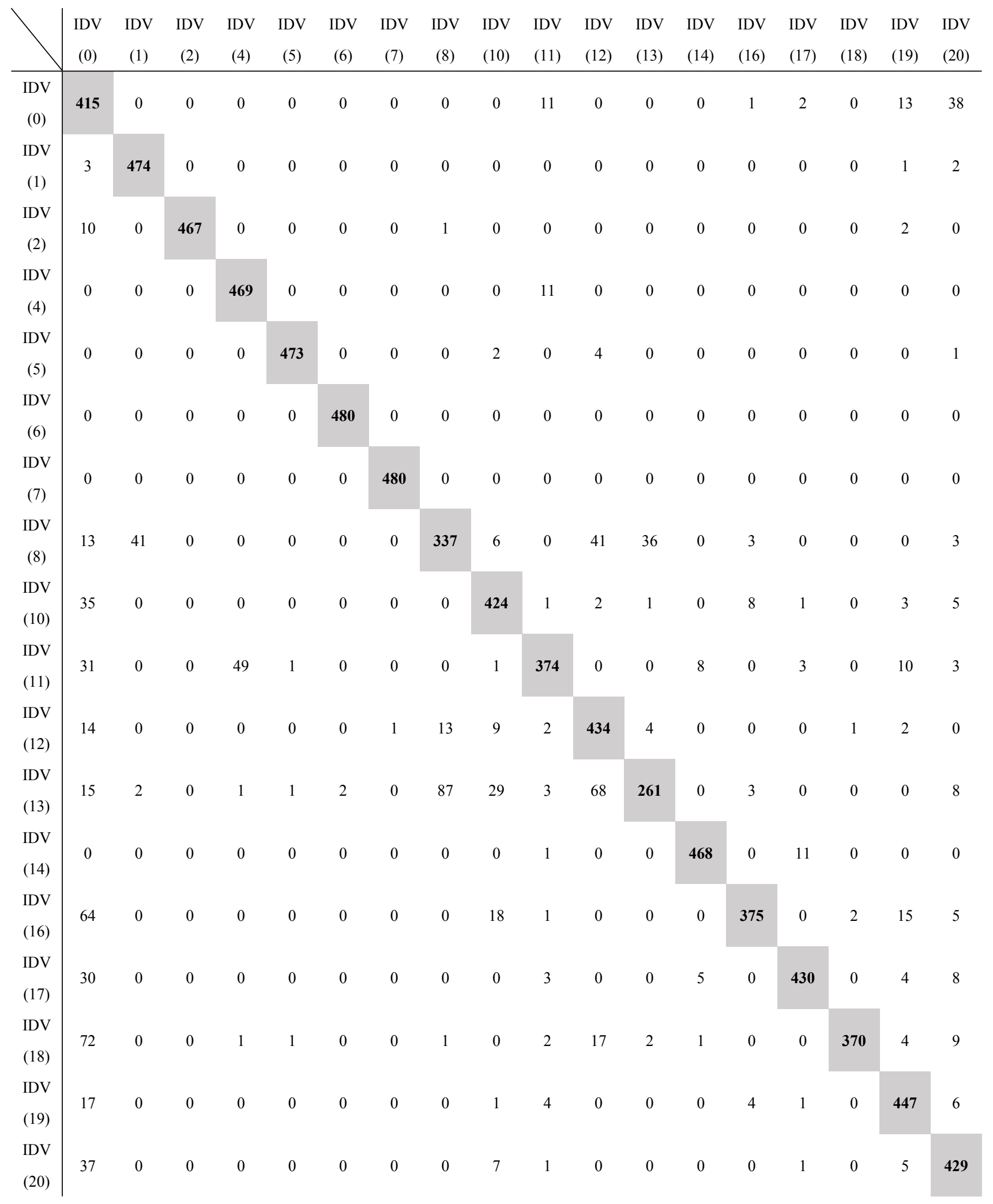

